\title{
Hostel: 0 estado da arte e considerações para futuras pesquisas
}

State of the scientific research on the hostel theme: considerations for future research

Estado del arte del tema albergue: consideraciones para ruturas investigaciones

http://dx.doi.org/10.18472/cvt.17n3.2017.1142

Álvaro Augusto Dealcides Silveira Moutinho Bahls 〈alvarobahls@edu.univali.br > Universidade do Vale do Itajaí (Univali), Balneário Camboriú, SC, Brasil

Yára Christina Cesário Pereira 〈yara@univali.br >

Universidade do Vale do Itajaí (Univali), Balneário Camboriú, SC, Brasil

OBSERVAÇÕES:

- Artigo baseado em dissertação. Autor: Álvaro Augusto Dealcides Silveira Moutinho Bahls. Título: Hostel: proposta conceitual, análise socioespacial e do panorama atual em Florianópolis (SC). Ano: 2015. Instituição: Universidade do Vale do Itajaí (Univali).

CRONOLOGIA DO PROCESSO EDITORIAL

Recebimento do artigo: 20-out-2015

Aceite: 22-ago-2017

FORMATO PARA CITAÇÃO DESTE ARTIGO

BAHLS, A. A. D. S. M.; PEREIRA, Y. C. C. Hostel: o estado da arte e considerações para futuras pesquisas. Caderno Virtual de Turismo. Rio de Janeiro, v. 17, n. 3, p. 50-65, dez. 2017.

REALIZAÇÃO

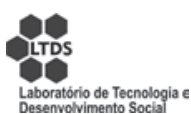

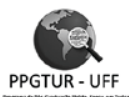

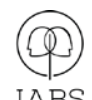

APOIO INSTITUCIONAL

EDIÇÃO

PATROCÍNIO

COPPE

UFR]

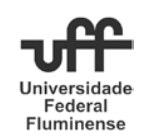

IPBS

1月:

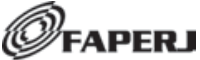




\section{RESUMO}

Os hostels são um tema carente de aprofundamento científico. Esse meio de hospedagem alternativo possui características que o diferenciam dos tradicionais. Não há, atualmente, uma classificação oficial sobre ele, por parte do Ministério do Turismo. Tem-se como objetivo principal apontar as lacunas de estudo existentes e sugerir áreas de pesquisa que auxiliem na disseminação dos hostels e em sua futura classificação. Isso é cumprido por meio do levantamento do estado da arte sobre o tema hostel, realizado entre os meses de agosto de 2013 e novembro de 2014, em um recorte temporal de 25 anos. As palavras-chave usadas foram: hostel e turismo backpacker. Essa coleta resultou em um total de 66 referências científicas. Conclui-se que, apesar de embrionário, o tema de estudo mostra-se promissor, com trabalhos concisos. No entanto, as áreas de pesquisa focam-se na gestão, marketing e público-alvo do tema, enquanto que os aspectos históricos, filosóficos e de conceptualização ainda não foram abordados coerentemente. Sugere-se que, anteriormente à produção científica sobre a gestão desse meio de hospedagem, seja incentivado o estudo sobre o conceito de hostel, principalmente no Brasil.

Palavras-chave: Hostel. Turismo Backpacker. Hospitalidade.

\section{ABSTRACT}

Hostels are a subject in need of scientific research. This alternative means of lodging has characteristics which differentiates them from traditional ones. Currently, there is not an official classification for it, by the Brazilian Ministry of Tourism. This paper has as main objective to point out the existing study gaps and suggest areas of research to assist in the dissemination of hostels and their future classification. This is accomplished through the research of the "state of the art" on the theme hostel, which took place between August 2013 and November 2014, in a time frame of 25 years. The key words used were: hostel and backpacker tourism. This collection resulted in a total of 66 scientific references. It concludes that, although embryonic, the subject of study is promising, with concise works. However, the research areas focus on management, marketing and target audience, while the historical, philosophical and conceptualization have not yet been addressed coherently. It is suggested that, prior to the scientific literature on management of the means of accommodation, is encouraged the study of the concept of hostel, mainly in Brazil.

Keywords: Hostel. Backpacker Tourism. Hospitality.

\section{RESUMEN}

Los albergues son un sujeto necesitado de profundización científica. Este medio alternativo de hospedaje cuenta con características que los diferencia de los tradicionales. Actualmente hay una clasificación oficial para esto, por el Ministerio de Turismo. Tiene como principal objetivo señalar las lagunas de estudio existentes y sugerir áreas de investigación para contribuir a la difusión de albergues y su futuro clasificación. Esto se logra a través del levantamiento del estado de la técnica en el albergue tema, que tuvo lugar entre agosto de 2013 y noviembre de 2014, en un plazo de 25 años. Las palabras clave utilizadas fueron: albergue y el turismo mochilero. Esta colección resultó en un total de 66 referencias científicas. Se concluye que, aunque embrionaria, el objeto de estudio es prometedor, con obras concisas. Sin embargo, las áreas de investigación se centran en la gestión, la comercialización y el tema público de la meta, mientras que el histórico, filosófico y conceptualización aún no se han abordado de manera coherente. Se sugiere que, antes de la literatura científica sobre la gestión de los medios de alojamiento, se alentó el estudio del concepto de hostal, principalmente en Brasil.

Palavras clave: Hostal. El turismo mochilero. Hospitalidad. 


\section{Introdução}

Os hostels são um meio de hospedagem alternativo com cunho social de extrema importância e significante participação econômica para o turismo (UNWTO, 2010). Eles encontram-se dentro do campo da hospitalidade e, consequentemente, dos meios de hospedagem, mas não dentro da hotelaria, pois são meios de hospedagem únicos, com filosofia, características físicas e serviços diferenciados (BAHLS, 2015; COBURN, 1950; GIARETTA, 2003; TROTTA, 1978). O caminho traçado pelos albergues da juventude, apesar de possuir similaridades, é distinto do da hotelaria (GIARETTA, 2003). Possui em sua fundação histórica o conceito da hospitalidade genuína, o qual dá origem ao primeiro meio de hospedagem dessa tipologia em Altena, Alemanha, em 1912 (COBURN, 1950). Após sua criação, a ideia de um local que pudesse abrigar jovens viajantes, promover o entendimento entre culturas, a conservação do patrimônio e do meio ambiente, decolou rapidamente (HEATH, 1962).

Da necessidade de supervisionar esses estabelecimentos, nasceu o "Comitê Central dos Albergues da Alemanha", atualmente nomeada de Hostelling International (HI) (HOSTELLING INTERNATIONAL, 2014). No entanto, há quem deseje possuir um albergue da juventude, sem, contudo, se filiar à associação e aderir às regras, tais como o limite de idade para usuários. Nascem, assim, os albergues da juventude independentes, intitulados a partir daqui como hostels, que compreendem qualquer empreendimento não associado à HI. Há quem considere os hostels como uma alternativa mais barata e mais rudimentar aos hotéis (CAMPOS, 2005), desconsiderando os acontecimentos socioespaciais que determinam suas características. Na verdade, eles nasceram em um contexto socioespacial e histórico único, adquirindo características físicas e serviços singulares (BAHLS, 2015; COBURN, 1950; HEATH, 1962; HOSTELLING INTERNATIONAL, 2014). Portanto, esse meio de hospedagem deve ser considerado em uma categoria única, digno de uma conceptualização oficial também singular, fiel à sua gênese, que pode estar mais próxima dos conceitos originais de hospitalidade do que os hotéis convencionais.

O problema de pesquisa deriva do fato de que, internacionalmente, os hostels estão bem difundidos e até mesmo conceituados por leis em alguns países, principalmente no continente europeu e América do Norte. Nesses locais, suas características singulares estão bem definidas, são tidos como parte de um fenômeno social e estão ligados diretamente à hospitalidade do local visitado, como é o exemplo da França, que possui um selo de qualidade aceito pelas autoridades nacionais como padrão (THE EUROPEAN CONSUMER CENTRES' NETWORK, 2009). No entanto, em âmbito nacional, esse segmento de mercado, por ser relativamente recente, encontra-se em estado de abandono por parte do Ministério do Turismo (MTur).

Apesar de sua importância socioeconômica, o MTur não contempla os hostels em sua nova matriz de classificação, por serem considerados meios de hospedagem coletiva e não individual, não havendo menção a eles no Sistema Brasileiro de Classificação de Meios de Hospedagem (SBClass) (SEBRAE, 2014). Em contato com o MTur, a organização simplesmente afirma que no "novo sistema serão sete matrizes, para os tipos: Hotel, Resort, Cama \& Café, Hotel Fazenda, Hotel Histórico, Pousada e Flat/Apart-Hotel. Nesse primeiro momento, os albergues não entraram na classificação" (MINISTÉRIO DO TURISMO, 2014). Além disso, os estudos científicos sobre o tema no Brasil encontram-se em estágio embrionário (FEDRIZZI, 2008; SANTOS; REJOWSKI, 2013).

Portanto, para que se possa classificar os hostels fielmente às suas características, é imprescindível (assim como para qualquer pesquisa científica) que ocorra, anteriormente à síntese de ideias e produção de conhecimento, uma revisão do tema a ser estudado, com a finalidade de compreender a essência deste 
(BRESSAN, 2008; MARKONI; LAKATOS, 2011; MARTINS, 2009). Os estudos de revisão são de suma importância, principalmente para os de caráter exploratório, como é o caso do tema deste artigo, pois permitem "mapeamentos, análises críticas, buscando colocar em evidência os temas e assuntos focalizados, as abordagens metodológicas, procedimentos e análises, [...] bem como as lacunas que podem estimular a produção de novas pesquisas" (VOSGERAU; ROMANOWSKI, 2014, p. 167). Adicionalmente, esse tipo de estudo possui a capacidade de definição de uma determinada área de pesquisa, favorece a compreensão das contribuições de estudos, assim como o campo e as disciplinas que a constituem,

apontando as necessidades de melhoria do estatuto teórico-metodológico, e mesmo as tendências de investigação. [Esses estudos] podem conter análises destinadas a comparar pesquisas sobre temas semelhantes ou relacionados; apontar [os] aportes teórico-metodológicos e sua compreensão em diferentes contextos, indicar as tendências e procedimentos metodológicos utilizados na área, apontar tendências das abordagens das práticas educativas (VOSGERAU; ROMANOWSKI, 2014, p. 168).

Assim, aqui pretende-se levantar o estado da arte do tema hostel, procurando determinar se há estudos que abordem a conceptualização dos hostels para auxiliar em uma futura classificação destes perante o MTur. Além disso, busca-se demonstrar quais campos de pesquisa são os mais carentes sobre o tema.

\section{METODOLOGIA}

Os objetivos foram cumpridos por meio de um levantamento do estado da arte sobre o tema hostel. De acordo com Vosgerau e Romanowski (2014), os estudos denominados de "estado da arte" encontram-se na categoria de pesquisas de mapeamento e são um aprofundamento da discussão sobre os resultados de um levantamento bibliográfico, permitindo identificar "temáticas recorrentes, apontando novas perspectivas, consolidando uma área de conhecimento e constituindo-se orientações de práticas pedagógicas para a definição dos parâmetros de formação de profissionais" (VOSGERAU; ROMANOWSKI, 2014, p. 170).

O primeiro levantamento foi realizado entre agosto de 2013 e junho de 2014. Constantes pesquisas foram realizadas até a última atualização, que ocorreu no dia 25 de novembro de 2014. Nesse dia delimitouse o fechamento do levantamento do estado da arte para o presente estudo e início da redação do presente artigo, pois os resultados obtidos começaram a se repetir e não foram obtidas novas publicações. No contexto internacional, foram utilizadas as bases de dados EBSCO, ScienceDirect, SciELO e Google Scholar (Google Acadêmico). No âmbito nacional foi realizada uma varredura na Biblioteca Brasileira de Teses e Dissertações (BDTD). Para artigos científicos, consultou-se o Portal de Periódicos Capes/MEC e os principais anais dos periódicos com qualificação mínima B2, sendo estes a revista Turismo, Visão e Ação (Univali), Turismo em Análise (USP), Revista Brasileira de Pesquisa em Turismo; Caderno Virtual do Turismo (UFRJ), Revista Rosa dos Ventos (UCS) e a Revista Brasileira de Ecoturismo (SBEcotur). Além desses, também foram consultados os anais da Associação Nacional de Pesquisa e Pós-graduação em Turismo (Anptur).

Foi determinado um recorte temporal de 25 anos (entre 1990 e 2014). Normalmente, um recorte considerado atual restringe-se, em média, a 05 anos. Optou-se por estendê-lo, pois, os resultados iniciais foram considerados insignificantes. Assim, buscou-se obter o máximo de resultados possíveis, por tratarse de um tema pouco pesquisado. As palavras-chave usadas foram: hostel, youth hostel, albergue, albergue da juventude, turismo da juventude, youth travel e backpacker. 


\section{RESULTADOS}

Foram coletadas 66 referências científicas, onde apenas 16 contemplam o tema principal do presente estudo, os hostels. Os Trabalhos de Conclusão de Curso (TCC) contribuíram com 05 referências nacionais, indicando um estágio ainda inicial da pesquisa acadêmica sobre esse tema, mas extremamente promissor, pois a maioria da pesquisa científica encontra-se sob domínio da faixa demográfica mais jovem de pesquisadores, os graduandos dos cursos de bacharelado em turismo e hospitalidade. Os demais trabalhos (50) dizem respeito à gestão dos hostels, ao público-alvo desse meio de hospedagem, denominado de turismo da juventude, e à hospitalidade. Os resultados sobre hospitalidade, aquela mais próxima de seu conceito puro, o de acolhimento incondicional a um estranho, ainda são, também, limitados.

A pesquisa sobre hostel também reflete isso. Percebe-se que a produção acadêmico-científica sobre o tema hostel é extremamente recente (Figura 1), tendo início significativo somente a partir do ano de 2000. Porém, há uma clara tendência de interesse científico pelo tema, o qual vem em exponencial crescimento, mostrando que essa tipologia de acomodação está figurando como um tema relevante e promissor de pesquisa.

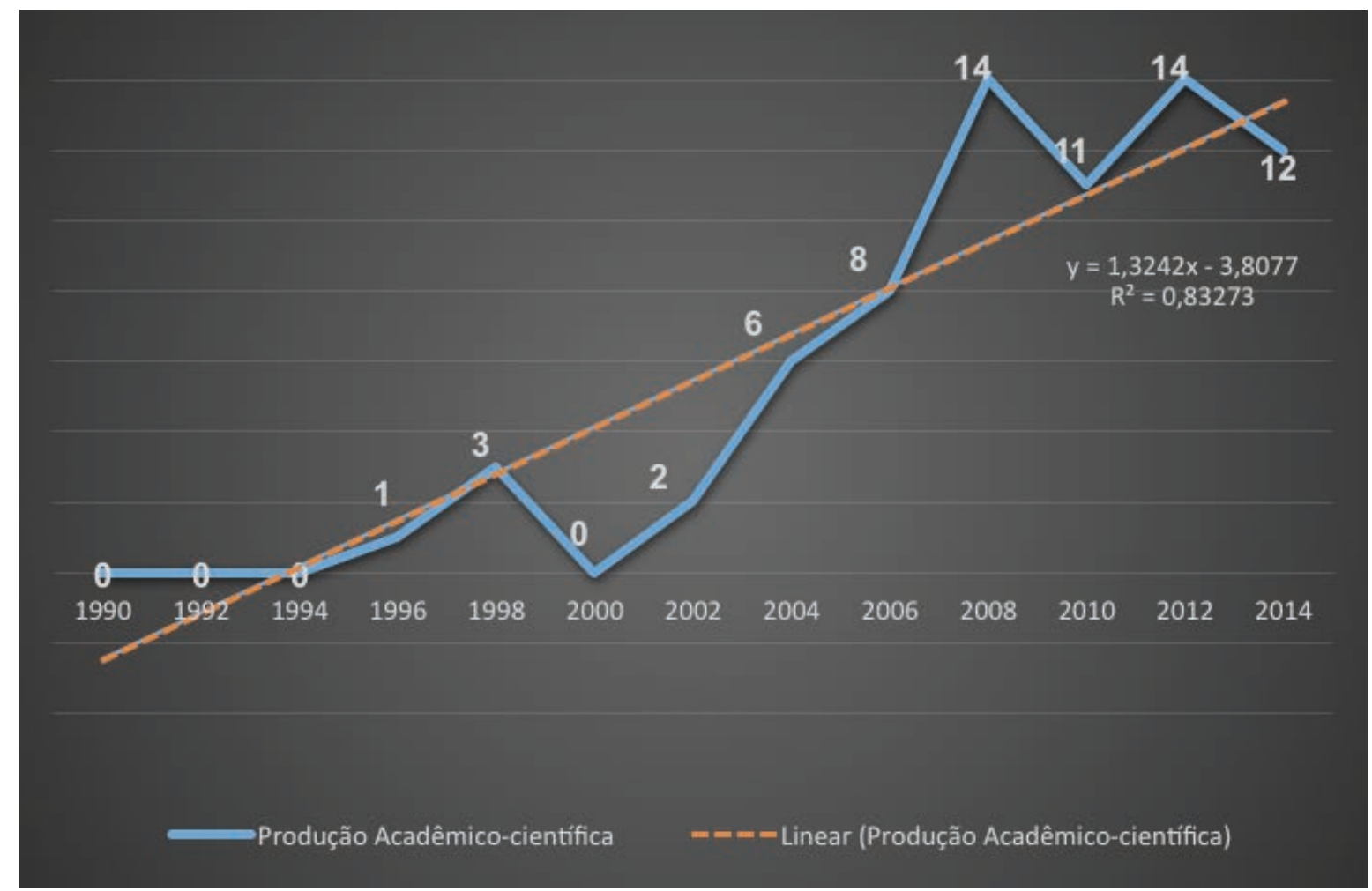

Figura 1 - Evolução cronológica da produção científica sobre o tema

Fonte: Elaborado pelo autor, 2014

Desde a metade da primeira década dos anos 2000 as pesquisas nacionais começaram a multiplicarse significativamente, devido aos estudos em hospitalidade, fomentado principalmente pelo curso de Hospitalidade da Universidade Anhembi-Morumbi e de Turismo e Hotelaria da Universidade do Vale do Itajaí, (Figura 2). Assim, o papel e a responsabilidade dessas duas instituições em propagar um conceito de hostel para uma futura classificação são de grande magnitude. 


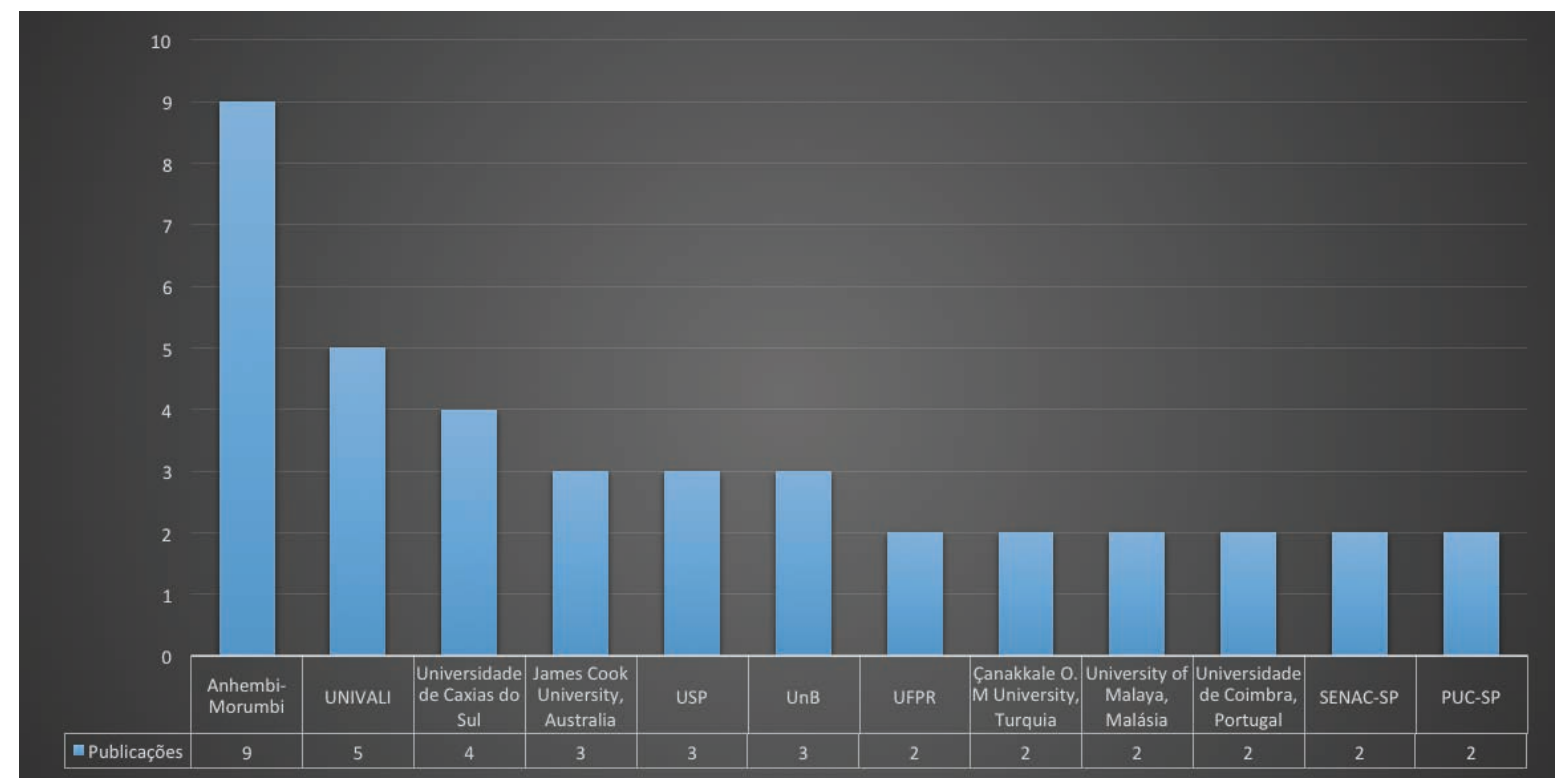

Figura 2 - Contribuição das instituições de ensino sobre o tema de pesquisa

Fonte: Elaborado pelo autor, 2014

Percebe-se a baixa contribuição de dissertações, apenas 03 contemplam os hostels de maneira direta, sendo que uma dessas contempla a rede HI (Figura 3). As 08 demais dissertações abordam o turismo backpacker e a hospitalidade em meios de hospedagem alternativos. Essas dissertações são, em sua maioria, realizadas em âmbito nacional e possuem pouca ou nenhuma comparação com o panorama internacional desse meio de hospedagem. O número de teses sobre esse tipo de acomodação é inexistente. As 03 teses relacionadas abordam a hospitalidade e contemplam os hostels superficialmente. Os artigos científicos dominam a produção acadêmica sobre o tema, talvez pelo fato de que podem ser produzidos de forma mais imediata, superando assim a produção de teses, que ficam a encargo de uma produção temporal mais morosa. Porém, nenhuma produção acadêmica aborda a história e/ou o conceito de hostel como tema dominante.

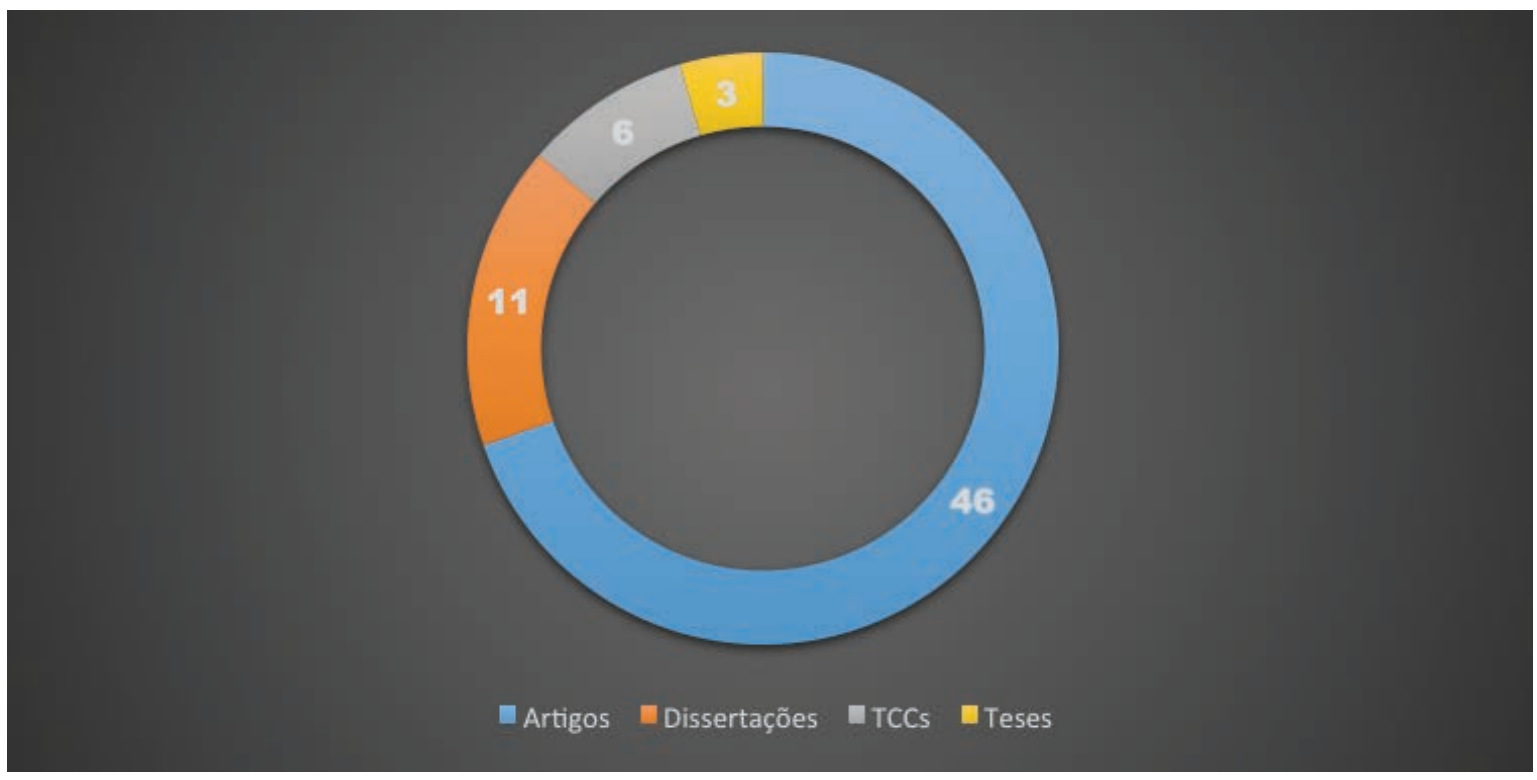

Figura 3 - Tipologia da produção acadêmico-científica do tema da pesquisa Fonte: Elaborado pelo autor (2014). 
Os periódicos de maior contribuição são Annals of Tourism Research com 6 trabalhos, RBTUR com 4, e Tourism Management, C.I.T, Revista Hospitalidade, Turismo - Visão e Ação e TURyDES com 3 cada (Figura 4). O periódico Annals of Tourism Research (ISSN 01607383) é considerado, dentro do meio acadêmico, como um dos mais bem-conceituados do turismo mundial. Possui um Journal Impact Factor/ JCR - ISI de 2.685 (o mais alto de todos os periódicos do turismo mundial), um H (Index) Scopus de 95 e um conceito Qualis (2013-2014) A1 (UNIVERSIDADE DO VALE DO ITAJAÍ, 2015). Conta com no mínimo o dobro de publicações de praticamente todas as demais organizações, mostrando a importância desse tema para o turismo mundial e como publicações sobre os hostels podem possuir um impacto significativo no meio acadêmico.

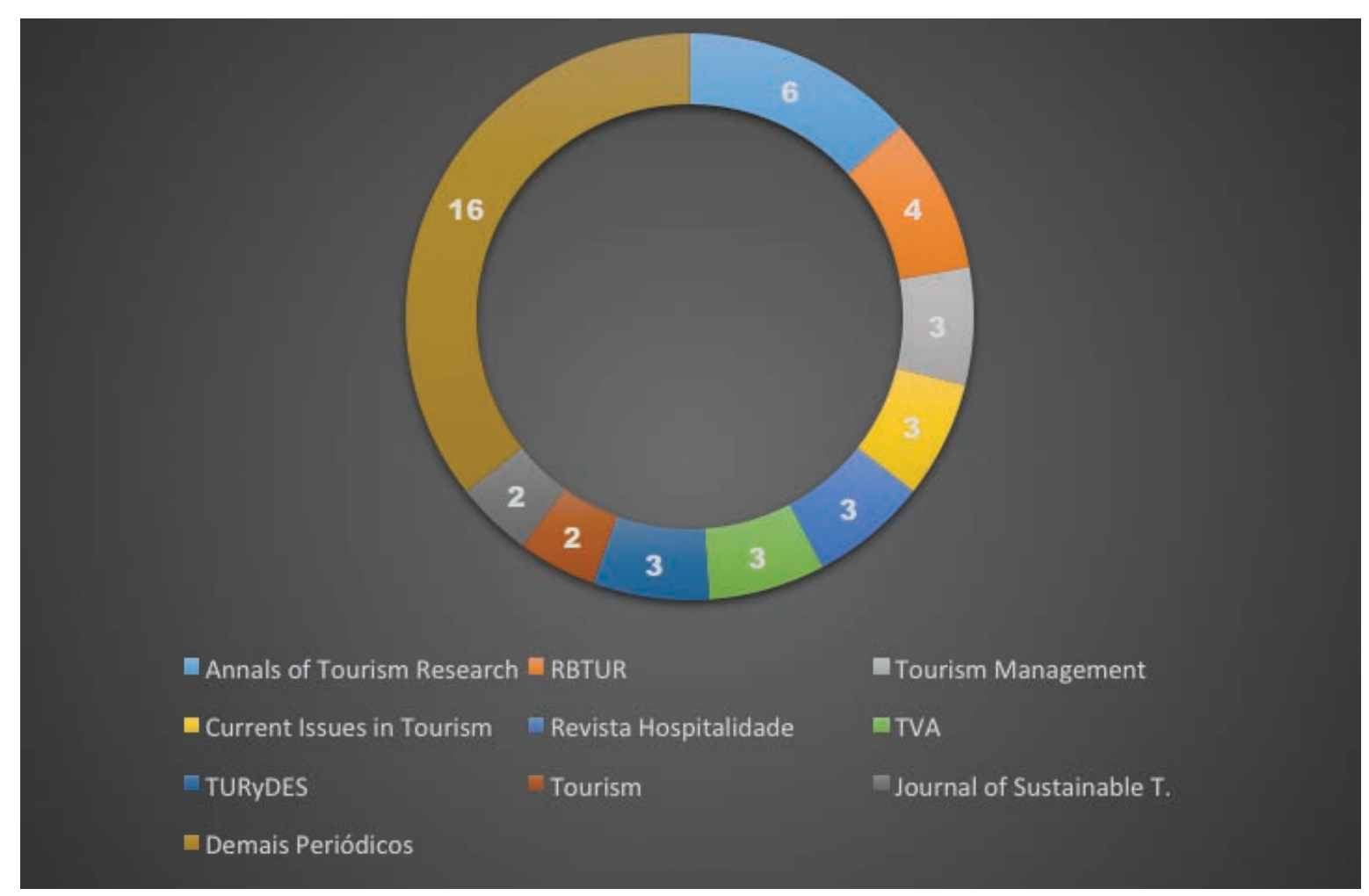

Figura 4 - Contribuição científica por periódico

Fonte: Elaborado pelo autor (2014).

Quanto à metodologia dos trabalhos, vale ressaltar que a maioria dos estudos não explicitavam o método usado, apenas as técnicas de pesquisa, uma falha aparentemente recorrente da produção nacional acadêmica em turismo. A apresentação do método científico no resumo e/ou no decorrer dos trabalhos analisados é praticamente inexistente. Com base em diversas fontes metodológicas (BRESSAN, 2008; DENCKER, 2007; LEAL, 2011; MARKONI; LAKATOS, 2011; MARTINS, 2009; NETTO, 2011; RICHARDSON, 2008), fez-se um esforço e exercício de dedução, porém, passível de erro, a fim de tentar classificar os trabalhos em categorias de metodologia de pesquisa (Figura 5). 


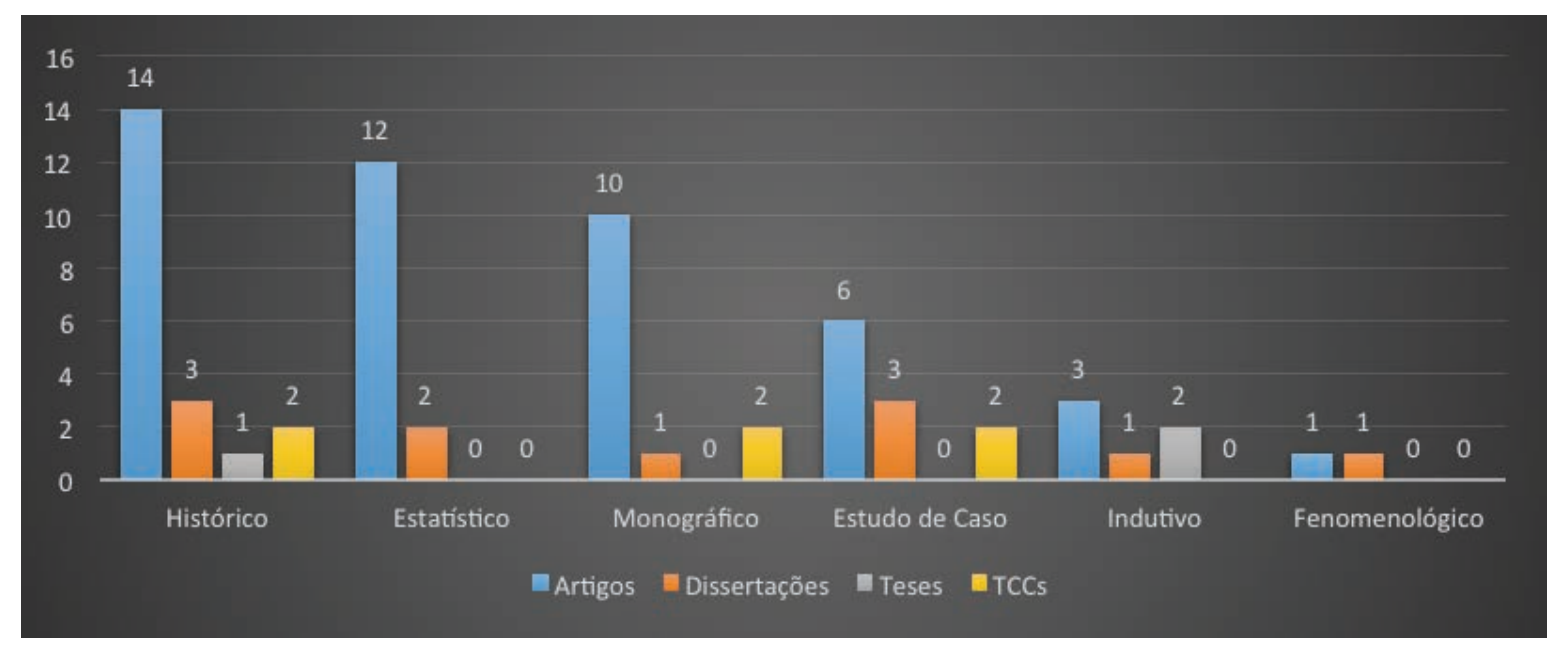

Figura 5 - Abordagem metodológica sobre o tema da pesquisa

Fonte: Elaborado pelo autor (2014).

Talvez pelo vínculo com a hospitalidade, é clara a preferência pela metodologia denominada histórica/etnográfica. Essa metodologia possui a capacidade de abordar profundamente fenômenos contemporâneos e históricos, individuais e grupais, em uma vasta amplitude espacial e temporal, de uma maneira contextualizada, investigativa, interpretativa e analítica (LEAL, 2011). Essa abordagem permite contemplar ambos os temas de maneira multifacetada (qualitativa, indutiva, etc.). Somente assim podese entender melhor a essência dos temas estudados, pois estes exprimem um contexto social e pessoal intrínseco de sua gênese.

Em segundo lugar aparece o método estático, como consequência de que os estudos na área de gestão e marketing, possivelmente, usam a estatística como principal ferramenta de pesquisa. Apesar de útil para o turismo, essa abordagem não possibilita a análise da essência de fenômenos sociais, os quais estão vinculados à essência do turismo. Os hostels, desde sua origem, são uma demonstração de hospitalidade da pessoa e do local visitados (COBURN, 1950; GIARETTA, 2003; HEATH, 1962), por isso são um fenômeno turístico e carecem, também, de uma abordagem social e qualitativa, para que se possa compreendê-los e analisá-los de forma adequada.

O método monográfico/bibliográfico aparece como terceira opção, possivelmente pelo fato de poder facilitar a pesquisa acadêmica, principalmente a de graduação, realizada dentro de salas de aula/pesquisa, minimizando saídas de campo. Em uma análise puramente quantitativa percebe-se a clara predominância dos artigos científicos e do método histórico sobre as demais formas de produção acadêmica (Tabela 1). 
Tabela 1 - Quantificação da produção científica por sua tipologia x metodologia

\begin{tabular}{|l|c|c|c|c|c|}
\hline & ARTIGOS & DISSERTAÇÕES & TESES & TCC & TOTAL \\
\hline HISTÓRICO & 14 & 3 & 1 & 2 & 20 \\
\hline ESTATÍSTICO & 12 & 2 & 0 & 0 & 14 \\
\hline MONOGRÁFICO & 10 & 1 & 0 & 2 & 13 \\
\hline ESTUDO DE CASO & 6 & 3 & 0 & 2 & 11 \\
\hline INDUTIVO & 3 & 1 & 2 & 0 & 6 \\
\hline FENOMENOLÓGICO & 1 & 1 & 0 & 0 & 2 \\
\hline TOTAL & 46 & 11 & 3 & 6 & 66 \\
\hline
\end{tabular}

Fonte: Elaborado pelo autor (2014).

O Brasil rendeu um número significativamente maior que os demais países, pois é o local da pesquisa onde foi feita uma varredura mais profunda. Percebe-se que o maior centro de pesquisa é o continente europeu, devido à sua tradição alberguista. Outro local significativo é a Austrália com cinco (5) trabalhos (Figura 6).

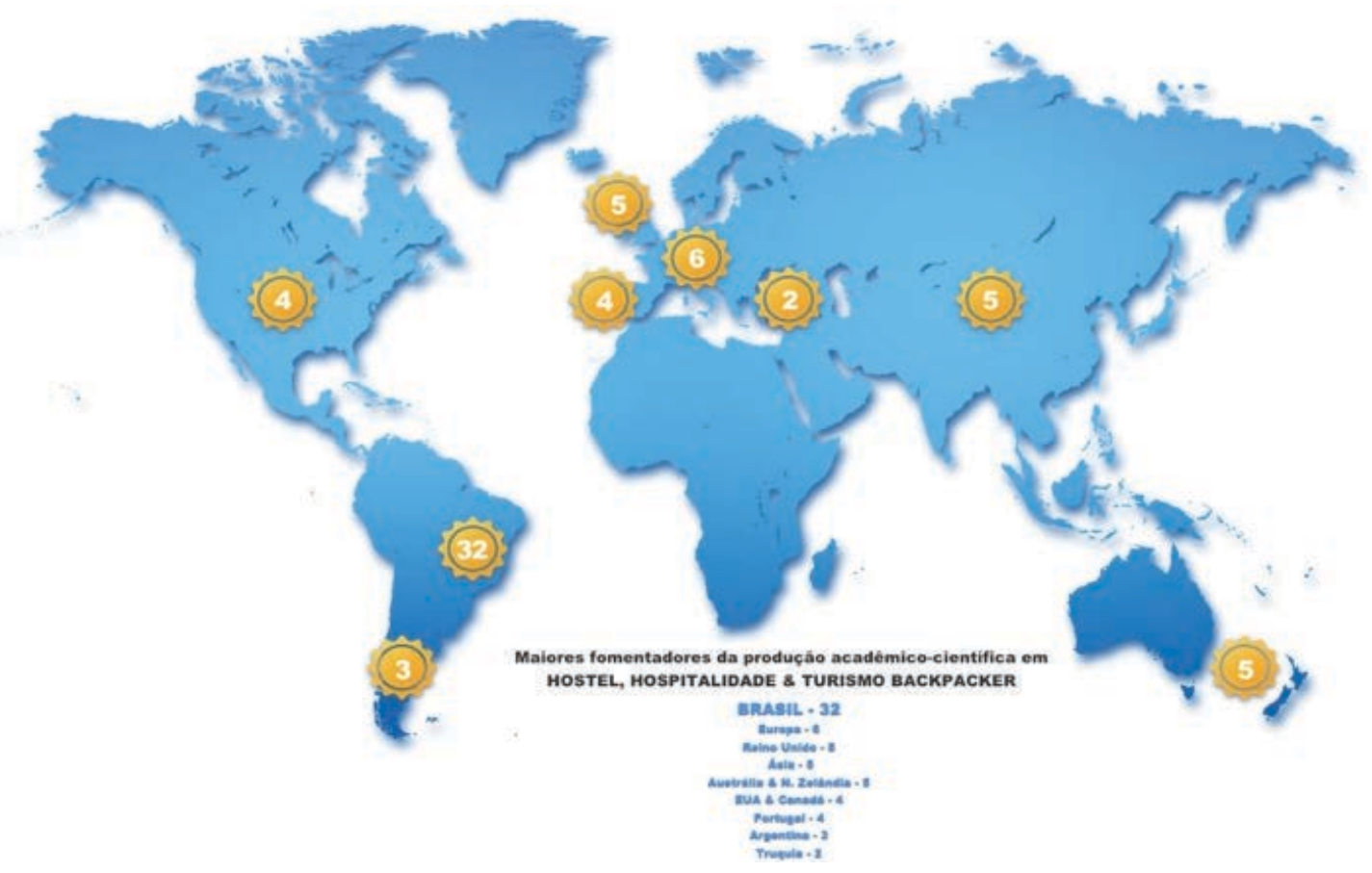

Figura 6 - Distribuição geográfica da produção científica do tema de pesquisa

Fonte: Elaborado pelo autor (2014).

Apesar dos dados apresentados acima, as informações mais relevantes sobre esses estudos são, na verdade, seus objetivos, resultados e considerações finais. Esses conteúdos são os mais variados, alguns com temas extremamente pertinentes ao abordado por este estudo. Outros, com caráter multidisciplinar, mostram que podem ser úteis como revisão teórica. Em uma análise puramente quantitativa, esses 
trabalhos perderiam seu contexto e significado. Portanto, a título de ilustração e de síntese, criou-se uma tabela que reúne oito trabalhos considerados relevantes para auxiliar a compor um quadro teórico do tema de estudo neste momento. Desses trabalhos, quatro merecem destaque (Tabelas 2 e 3).

Tabela 2 - Resumo da produção acadêmico-científica sobre o tema hostel

\begin{tabular}{|c|c|c|c|c|c|}
\hline & Título & Autor(es) e Ano & Instituição & Base & Fonte \\
\hline 01 & $\begin{array}{l}\text { Backpacker hostels and } \\
\text { their guests: attitudes } \\
\text { and behaviors relating to } \\
\text { sustainable tourism }\end{array}$ & $\begin{array}{c}\text { (FIRTH; HING, } \\
\text { 1999) }\end{array}$ & $\begin{array}{c}\text { The Hotel } \\
\text { School, Hotel } \\
\text { Intercontinental } \\
\text { Sydney }\end{array}$ & Capes & $\begin{array}{c}\text { Tourism } \\
\text { Management v. 20, } \\
\text { n. } 2\end{array}$ \\
\hline 02 & $\begin{array}{l}\text { A Lifestyle Segmentation } \\
\text { Analysis of the } \\
\text { Backpacker Market in } \\
\text { Scotland }\end{array}$ & $\begin{array}{l}\text { (NASH; THYNE; } \\
\text { DAVIES, 2006) }\end{array}$ & $\begin{array}{l}\text { The Robert } \\
\text { Gordon } \\
\text { University, } \\
\text { Scottland }\end{array}$ & EBSCO & $\begin{array}{l}\text { Journal of Quality } \\
\text { in H. \& Tourism; v. } \\
\text { 5, n. } 2\end{array}$ \\
\hline 03 & $\begin{array}{l}\text { Hospedaria Vasque. } \\
\text { Cultura, raça, gênero e } \\
\text { expediente num oásis da } \\
\text { Mauritânia }\end{array}$ & (SILVA, 2006) & $\begin{array}{l}\text { Universidade } \\
\text { Nova de Lisboa }\end{array}$ & SciELO & $\begin{array}{l}\text { Etnográfica v. 10, } \\
\text { n. } 2\end{array}$ \\
\hline 04 & $\begin{array}{l}\text { Undergraduate Students' } \\
\text { Satisfaction with Hostel } \\
\text { and Sense of Attachment } \\
\text { to Place }\end{array}$ & $\begin{array}{c}\text { (KHOZAEI; } \\
\text { HASSAN; } \\
\text { KHOZAEI, 2010) }\end{array}$ & $\begin{array}{c}\text { Science } \\
\text { Publications }\end{array}$ & Capes & $\begin{array}{c}\text { American J. of } \\
\text { Applied Science, v. } \\
\text { 3, n. } 3\end{array}$ \\
\hline 05 & $\begin{array}{l}\text { Turismo Backpacker } \\
\text { em São Paulo: um } \\
\text { Estudo sobre a Rede de } \\
\text { Albergues HI Hostel }\end{array}$ & (FILHO, 2010) & $\begin{array}{l}\text { Universidade } \\
\text { Anhembi } \\
\text { Morumbi }\end{array}$ & BDTD & Dissertação \\
\hline 06 & $\begin{array}{l}\text { Exploring service quality } \\
\text { and servicescape of the } \\
\text { best backpacker hostel in } \\
\text { Asia. }\end{array}$ & $\begin{array}{c}\text { (MUSA; } \\
\text { THIRUMOORTHI, } \\
\text { 2011) }\end{array}$ & $\begin{array}{l}\text { University } \\
\text { of Malaya, } \\
\text { Malaysia }\end{array}$ & EBSCO & $\begin{array}{l}\text { Current Issues in } \\
\text { Tourism; v. 14, n. } 2\end{array}$ \\
\hline 07 & $\begin{array}{l}\text { Estudo sobre a } \\
\text { Relação entre o Jovem } \\
\text { Universitário e os } \\
\text { Albergues da Juventude }\end{array}$ & $\begin{array}{c}\text { (CICCIO; } \\
\text { TEIXEIRA; } \\
\text { SALLES, 2011) }\end{array}$ & $\begin{array}{l}\text { Universidade } \\
\text { Anhembi } \\
\text { Morumbi }\end{array}$ & EBSCO & TURyDES; v. 4, n. 10 \\
\hline 08 & $\begin{array}{l}\text { Gap theory based analysis } \\
\text { of user expectation and } \\
\text { satisfaction: The case of a } \\
\text { hostel building }\end{array}$ & $\begin{array}{l}\text { LAI, J. H. K. } \\
\text { (2013) }\end{array}$ & $\begin{array}{c}\text { The Hong Kong } \\
\text { Polytechnic } \\
\text { University }\end{array}$ & Capes & $\begin{array}{c}\text { Building and } \\
\text { Environment, v. } 69\end{array}$ \\
\hline
\end{tabular}

Fonte: Elaborado pelo autor (2014). 
Tabela 3 - Análise das principais produções acadêmico-científicas em Hostel

\begin{tabular}{|c|c|c|c|c|c|}
\hline & Título & $\begin{array}{l}\text { Autor(es) } \\
\text { e Ano }\end{array}$ & Instituição & Base & Fonte \\
\hline 01 & $\begin{array}{l}\text { Investigar que tipos de } \\
\text { práticas ecologicamente } \\
\text { corretas estão sendo } \\
\text { implementadas pelos seis } \\
\text { albergues para mochileiros e } \\
\text { determinar se a realização de } \\
\text { práticas ecológicas influencia } \\
\text { os backpackers na escolha de } \\
\text { acomodação. }\end{array}$ & $\begin{array}{l}\text { Estudo de } \\
\text { caso }\end{array}$ & $\begin{array}{l}\text { Documentação } \\
\text { direta } \\
\text { exploratória, } \\
\text { questionários } \\
\text { estruturados }\end{array}$ & $\begin{array}{l}\text { Entendendo o meio } \\
\text { ambiente e mochileiros, } \\
\text { os albergues ajudam } \\
\text { planejadores de turismo } \\
\text { local a determinar se este } \\
\text { mercado deve continuar } \\
\text { a ser incentivado, sem } \\
\text { planejamento ou controles } \\
\text { por parte do governo local } \\
\text { e da comunidade. }\end{array}$ & $\begin{array}{c}\text { Ele questionou a percepção } \\
\text { comum de que as } \\
\text { pequenas empresas locais } \\
\text { atraindo turistas de baixa } \\
\text { intensidade são mais } \\
\text { desejáveis, se turismo } \\
\text { sustentável deve ser } \\
\text { mantido. }\end{array}$ \\
\hline 03 & $\begin{array}{c}\text { Acompanhar como o turismo } \\
\text { transforma e apropria o local. } \\
\text { Observar novas configurações } \\
\text { sociais que reciclam a força } \\
\text { atrativa do destino em } \\
\text { questão }\end{array}$ & $\begin{array}{l}\text { Abordagem } \\
\text { Etnográfica }\end{array}$ & $\begin{array}{c}\text { Pesquisa } \\
\text { bibliográfica e } \\
\text { entrevistas }\end{array}$ & $\begin{array}{l}\text { Esclareceu como o Islã } \\
\text { pode oferecer alternativas } \\
\text { de legitimação de } \\
\text { comportamentos, face a } \\
\text { códigos sociais rígidos e } \\
\text { pouco preparados para } \\
\text { a mudança resultante do } \\
\text { advento do turismo. }\end{array}$ & $\begin{array}{l}\text { O sucesso encontra-se } \\
\text { no domínio das relações } \\
\text { transnacionais. As } \\
\text { mulheres têm maior } \\
\text { capacidade de integração } \\
\text { no mercado turístico } \\
\text { internacional. O processo } \\
\text { de globalização levou } \\
\text { à subversão de valores } \\
\text { sociais, libertando alguns } \\
\text { mais do que outros. }\end{array}$ \\
\hline 05 & $\begin{array}{l}\text { Analisar o turismo backpacker } \\
\text { na cidade de São Paulo, com } \\
\text { foco central nos hostels da } \\
\text { rede Hi Hostels no ano de } \\
2009\end{array}$ & $\begin{array}{l}\text { Estudo de } \\
\text { caso }\end{array}$ & $\begin{array}{c}\text { Análise de } \\
\text { bibliografia, } \\
\text { entrevista } \\
\text { semiestruturada }\end{array}$ & $\begin{array}{l}\text { Destaca-se que essa } \\
\text { modalidade de turismo } \\
\text { não é reconhecida no } \\
\text { Brasil pelo Governo } \\
\text { Federal como prioridade, } \\
\text { nem como segmento, } \\
\text { diferentemente de alguns } \\
\text { países desenvolvidos }\end{array}$ & $\begin{array}{l}\text { Isso se reflete na } \\
\text { população brasileira que } \\
\text { em geral desconhece } \\
\text { esse o segmento, muitas } \\
\text { vezes relacionando os } \\
\text { hostels com os albergues } \\
\text { da juventude de caráter } \\
\text { assistencialista }\end{array}$ \\
\hline 07 & $\begin{array}{c}\text { Discorre sobre as razões } \\
\text { pelas quais os jovens não têm } \\
\text { como prioridade de escolha } \\
\text { os albergues de juventude } \\
\text { ou hostels como meio } \\
\text { de hospedagem em suas } \\
\text { viagens. }\end{array}$ & $\begin{array}{l}\text { Estudo de } \\
\text { caso }\end{array}$ & $\begin{array}{l}\text { Exploratória, } \\
\text { questionários e } \\
\text { entrevistas }\end{array}$ & $\begin{array}{c}\text { Os jovens não se } \\
\text { hospedam em hostel } \\
\text { porque não o conhece } \\
\text { como meio de } \\
\text { hospedagem, muitas vezes } \\
\text { confundindo-o com os } \\
\text { albergues da prefeitura. }\end{array}$ & $\begin{array}{c}\text { A minoria amostrada que } \\
\text { afirmou conhecer e utilizar } \\
\text { os albergues da juventude } \\
\text { o faz pela questão do preço } \\
\text { baixo. }\end{array}$ \\
\hline
\end{tabular}

Fonte: Elaborado pelo autor (2014).

De todos os resultados provenientes dessa pesquisa, nenhum aborda como tema principal a conceptualização dos hostels. Com exceção dos livros de Giaretta (2003) e Trotta (1978), não há outra publicação do gênero que analise a história desse meio de hospedagem, no Brasil, a fim de compreender seu papel no turismo atual. Com exceção de Bahls (2015), nenhum profundo esforço acadêmico foi feito, até o momento, para saber quais são suas características singulares que os diferenciam dos demais meios de hospedagem tradicionais.

Há estudos que contemplam uma breve conceptualização dos hostels em suas fundamentações teóricas, mas não vão a fundo na essência destes. Muitas vezes abordam esse meio de hospedagem de forma superficial e equivocada, definindo-o como um meio de hospedagem econômica que visa prover apenas o mínimo de conforto, higiene e segurança aos hóspedes (CAMPOS, 2005). Sabe-se que os hostels vão muito além disso e são, em sua essência, um local de interação e entendimento entre pessoas (BAHLS, 2015; COBURN, 1950; GIARETTA, 2003; HEATH, 1962). Esses equívocos podem ocorrer pelo preconceito perante esse recente meio de hospedagem alternativo e pela falta de estudos relacionados à origem e conceptualização dos hostels. 
Os estudos nas áreas de gestão, os quais apresentam um estado mais avançado de pesquisa, são extremamente importantes e devem ser fomentados e realizados. Não obstante, é necessária que se conheça a essência de um tema para que se possa geri-lo de maneira adequada. O conceito de hostel não é tão simplório quanto alguns autores assim o consideram, e sua história, que determina suas características, não é assunto que não se deva discutir. Pelo contrário, é de extrema importância que se saiba o histórico e a essência desse meio de hospedagem para que se possa classificá-lo adequadamente.

Portanto, as principais áreas de estudo a serem fomentadas, em relação aos hostels, são a histórica/ filosófica e, principalmente, a conceitual, pois esta última tende a reunir todas as duas áreas mencionadas anteriormente. Os conceitos nada mais são do que um estágio avançado ou a materialização de uma ideia. Consequentemente, eles são cruciais para os processos psicológicos, como a categorização, inferência, memória, aprendizagem e tomada de decisão (LIZARDO, 2013). O processo onde um conceito é inferido, através de múltiplas observações, é chamado processo dedutivo ou indutivo. Conclusões inferidas a partir de observações múltiplas podem ser testadas por observações adicionais, resultando em conhecimento científico (MARGOLIS; LAURENCE, 1999).

No sentido figurativo, a pesquisa sobre os hostels é como uma árvore, composta de três áreas: raízes (área histórica); caule (área conceitual) e folhas e frutos (área temática). Atualmente essa árvore encontrase sem raízes, a pesquisa em turismo apresenta-se sem nenhum estudo aprofundado sobre a gênese alberguista brasileira. Possui um caule fino e frágil, pela falta de pesquisas em conceitualização desse meio de hospedagem. Nas pesquisas atuais, esses conceitos compõem apenas o referencial teórico e são meramente de caráter bibliográfico, sem pesquisas aplicadas em campo, portanto, geralmente pecam em profundidade e coerência histórica e filosófica. Além disso, as folhas e frutos, que representam os mais diversos temas de pesquisa, são relativamente unilaterais, concentrando-se principalmente no campo da gestão, deixando de se ramificar em outras áreas e disciplinas. Portanto, o fomento a estudos sobre a história desse meio de hospedagem tende a fortalecer essas raízes e, consequentemente, criar um conceito forte e bem definido (Figura 7).

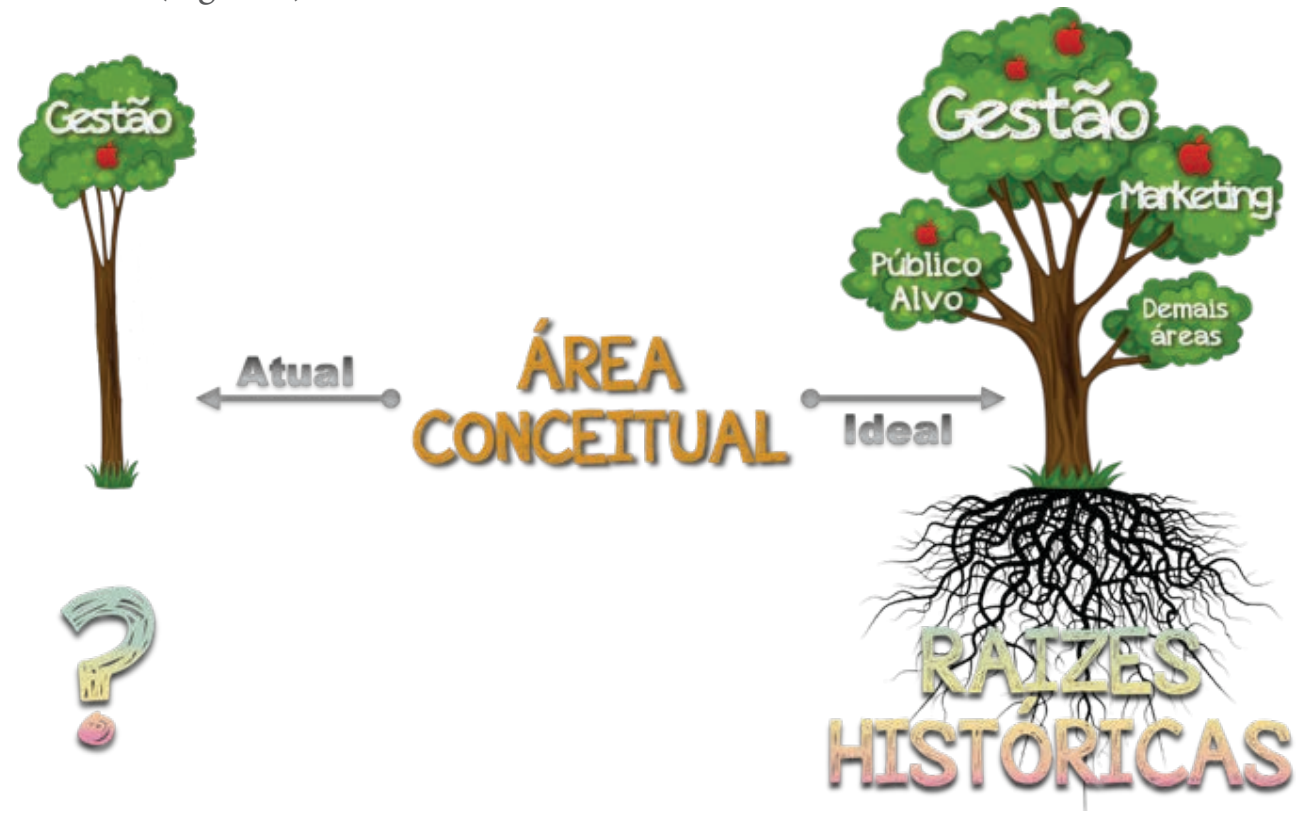

Figura 7 - Ilustração das áreas de pesquisa sobre o tema hostel

Fonte: Elaborado pelo autor (2015). 
As formulações lógicas que compõem os estudos das ciências sociais aplicadas não podem ser criadas sem um sistema de referência, um deles nossa herança cultural. A fim de estudar cientificamente determinados aspectos da vida humana, pode-se, por meio da análise histórica e da criação de conceitos, entender um fenômeno social (LIZARDO, 2013). Sem os acontecimentos socioespaciais (SANTOS, 2013), e para Ander-Egg "sem conceitos ou, para ser mais preciso, sem um sistema conceptual, não é possível o método científico e, consequentemente, a ciência" (1978 apud MARKONI; LAKATOS, 2011, p. 114). Espera-se que um conceito de hostel seja elaborado a partir de sua história e filosofia, que carecem de estudos por parte do meio acadêmico brasileiro.

\section{CONSIDERAÇÕES FINAIS}

O turismo da juventude é extremamente importante para o turismo contribuindo para o desenvolvimento econômico e social dos destinos (UNWTO, 2008). O perfil dessa "juventude" é interativo, ambientalmente consciente, sedento por cultura, viaja pelo destino visitado por mais tempo e em maior profundidade (UNWTO, 2010). Esse perfil tem nos hostels seu maior meio de hospedagem (GIARETTA, 2003). No entanto, a pesquisa acadêmico-científica sobre esse tema é recente, assim como é o advento desse meio de hospedagem no Brasil, carecendo, assim, de aprofundamento. Para Soares e Maciel (2000, p. 4), os estudos de revisão são necessários "no processo de evolução da ciência, a fim de que se ordene periodicamente o conjunto de informações e resultados já obtidos", pois organizam e configuram os campos de pesquisas emergentes, as perspectivas mais investigadas, assim como as carências do tema investigado.

Conclui-se que, apesar de embrionário, o estado da arte mostra-se promissor, em crescimento quantitativo com produções oriundas da graduação mostrando que o meio acadêmico em formação está se interessando pelo tema, e qualitativo com trabalhos concisos e pertinentes. Os hostels e a hospitalidade, um binômio inseparável (BAHLS, 2015), prometem ser um campo de pesquisa acadêmico-científica interessante e carente de exploração. Outra importante conclusão reside no fato de que apesar da diversidade e quantidade de artigos e dissertações sobre o tema, nenhum dos trabalhos analisados aborda as características físicas e/ou uma classificação oficial desse meio de hospedagem perante os órgãos públicos responsáveis. $\mathrm{O}$ fomento a essas pesquisas é fundamental para o desenvolvimento adequado desse novo segmento de mercado, resultando em um processo multidisciplinar, essencial para a internacionalização das instituições de ensino brasileiras.

Há indícios de que o estágio embrionário e o "preconceito" com o tema, desde a gestão à pesquisa, se dá, primeiramente, entre outros fatores, à relativa recente chegada desse meio de hospedagem ao Brasil (década de 1960-70) em comparação a outros países americanos (E.U.A. e Canadá na década de 1920). Em um segundo momento, os hostels são vistos, por parte da literatura tradicional em meios de hospedagem (BRAGA, 2003; FERREIRA, 1975; FERRI; RUSCHMANN, 2000; GARCIA, 2004; VIEIRA; CÂNDIDO, 2003), como apenas uma opção simplória e econômica aos hotéis convencionais, oferecendo acomodações com um mínimo de conforto, higiene e segurança a pessoas em viagens com baixo orçamento financeiro. Na verdade, os hostels vão muito além de proporcionar acomodação a baixo custo e há, atualmente, opções de alto custo, considerados hostels boutiques, que oferecem acomodações com alto padrão e refinamento tanto em sua estrutura física como em seus serviços. O que difere, essencialmente, um hotel de um hostel, é que o último é um meio de hospedagem com uma gênese totalmente única e diferenciada e, portanto, raízes filosóficas diferentes dos hotéis, pois os hostels procuram a sociabilização dos hóspedes, em 
primeiro lugar, assim como o contato dos visitantes com a cultura do local visitado (BAHLS, 2015; COSTA; FRANCO; HOFFMANN, 2013; GIARETTA, 2003; HEATH, 1962; HOSTELLING INTERNATIONAL, 2014; NASH; THYNE; DAVIES, 2006; PEARCE; FOSTER, 2007; TROTTA, 1978; UNWTO, 2008).

Outros estudos, como o de Bahls (2015), indicam que a principal razão pela qual os hostels enfrentam dificuldades de implantação no Brasil se dá pela diferença entre a essência da hospitalidade brasileira e a essência da hospitalidade genuína. A primeira nasce estritamente do interesse e das relações comerciais entre Brasil Colônia e Portugal. A segunda, de acordo com Gotman (2005), é uma dádiva, desinteressada, e é sob essa última que os hostels foram fundados. Espera-se que esse artigo contribua para uma gradativa mudança no modo como os pesquisadores abordam o tema.

Vale ressaltar que há limitações de pesquisa, como o fato de que o universo a ser pesquisado (as bases de dados, os periódicos e indexadores) é virtualmente infinito, pois atualmente a velocidade de lançamento e publicação de artigos e novos periódicos, devido à Internet, em diferentes partes do mundo e em diversos idiomas, dificulta a reunião de um montante de trabalhos definitivo, razão pela qual se deve continuar pesquisando, constantemente, o tema em questão. Além disso, não foi possível obter acesso a outras bases de dados internacionais como Taylor e Francis, SAGE e EMERALD. É necessária, em um futuro próximo, uma nova busca nas respectivas bases de dados que faltaram neste presente estudo. Um levantamento histórico dos hostels e albergues da juventude em diversos estados, mas com foco no estado do Rio de Janeiro, local de sua origem, e no estado de São Paulo, que possui o maior número de estabelecimentos do País, é de suma importância para o entendimento da essência dos hostels e, consequentemente, para sua futura classificação.

\section{REFERÊNCIAS}

BAHLS, Á. A. D. S. M. Hostel: proposta conceitual, análise socioespacial e do panorama atual em Florianópolis (SC). Dissertação de mestrado acadêmico em Turismo e Hotelaria - Programa de PósGraduação em Turismo e Hotelaria (PPGTH), Balneário Camboriú. Universidade do Vale do Itajaí (Univali), p. 256, Julho 2015.

BRAGA, R. Dicionário de Turismo. São Paulo: Uniletras, 2003.

BRASIL. Ministério do Turismo. Respostas protocolo 72550000271201453. Gmail, o8 Dezembro 2014. Disponivel em: 〈alvarobahls@gmail.com〉. Acesso em: 08 dez. 2014.

BRESSAN, S. J. Fundamentos das Ciências Sociais. ljuí: Unijuí, 2008.

CAMPOS, J. R. V. Introdução ao universo da hospitalidade. Campinas: Papirus, 2005.

CICCIO, G. P. D.; TEIXEIRA, G. D. C.; SALLES, M. D. R. R. Estudo sobre a relação entre o jovem universitário da cidade de São Paulo e os Albergues da Juventude. TURyDES, EUMED, v. 4, n. 10, Julho 2011.

COBURN, O. Youth Hostel Story. Londres: The National Council of Social Service, 1950.

COSTA, H. A.; FRANCO, A. F.; HOFFMANN, V. E. Cooperação entre pequenas empresas do turismo e competitividade: estudo de hostels no Rio de Janeiro. X SEMINÁRIO DA ASSOCIAÇÃO NACIONAL DE PESQUISA E PÓS-GRADUAÇÃO EM TURISMO - ANPTUR, p. 01-20, 09 de Outubro de 2013. 
DENCKER, A. D. F. M. Pesquisa em Turismo - Planejamento, métodos e técnicas. São Paulo: Futura, 2007.

FEDRIZZI, V. L. F. Dissertações de Mestrado dos Programas de Pós-Graduação em Turismo: análise das temáticas e citações. 2014. Biblioteca Digital de Teses e Dissertações da Universidade de São Paulo, São Paulo, 2014.

FERREIRA, F. L. Dicionário brasileiro de turismo. Rio de Janeiro: Colorama, 1975.

FERRI, C.; RUSCHMANN, D. V. M. Termos gerais em hotelaria. Turismo - Visão e Ação (Glossário), v. 2, n. 4, p. 35-51, 2000.

FILHO, W. G. Turismo Backpacker na cidade de São Paulo: um estudo sobre a rede de albergues HI. São Paulo: Dissertação de mestrado em Hospitalidade, da Universidade Anhembi Morumbi, 2010.

FIRTH, T.; HING, N. Backpacker hostels and their guests: attitudes and behaviours relating to sustainable tourism. Tourism Management, Sydney, v. 20, p. 251-254, 1999.

GARCIA, M. X. Vocabulário para o Turismo: português/inglês. São Paulo: SBS, 2004.

GIARETTA, M. J. Turismo da Juventude. Barueri: Manole, 2003.

GOTMAN, A. Revista Hospitalidade, v. 6, n. 2, p. 3-27, 23 dez. 2005.

HEATH, G. Richard Schirrmann - The first youth hosteller. Copenhaguem: International Youth Hostel Federation, 1962.

HOSTELLING INTERNATIONAL. About Us. Hostelling International, 2014. Disponivel em: 〈https://www. hihostels.com/about-hi/about-hostelling-internationalı. Acesso em: 27 out. 2014.

KHOZAEI, F.; HASSAN, A. S.; KHOZAEI, Z. Undergraduate Students' Satisfaction with Hostel and Sense of Attachment to Place: Case Study of University Sains Malaysia. American Journal of Engineering and Applied Sciences, v. III, n. 3, p. 516-520, 2010. ISSN DOI: 10.3844/ajeassp.2010.516.520.

LAI, J. H. K. Gap theory based analysis of user expectation and satisfaction: The case of a hostel building. Building and Environment, Elsevier, v. 69, p. 183-193, 2013.

LEAL, E. J. M. Produção acadêmico-científica: a pesquisa e o ensaio. Itajaí: Universidade do Vale do Itajaí, 2011.

LIZARDO, 0. Re-conceptualizing Abstract Conceptualization in Social Theory: The Case of the "Structure" Concept. Journal for the Theory of Social Behaviour, John Wiley \& Sons Ltd., v. 43, n. 2, p. 155-180, 2013. ISSN: 0021-8308.

MARGOLIS, E.; LAURENCE, S. Concepts and Cognitive Science. In: MARGOLIS, E.; LAURENCE, S. Concepts: Core Readings. Massachucets: MIT, 1999. p. 3-81.

MARKONI, M. D. A.; LAKATOS, E. M. Metodologia Científica. 6. ed. São Paulo: Atlas, 2011.

MARTINS, G. D. A. Metodologia da investigação científica para ciências sociais aplicadas. São Paulo: Editora Atlas, 2009.

MUSA, G.; THIRUMOORTHI, T. Red Palm: exploring service quality and servicescape of the best backpacker hostel in Asia. Current Issues in Tourism, Taylor \& Francis, v. 14, n. 2, p. 103-120, Março 2011. ISSN DOI: 10.1080/13683500903511125. 
NASH, R.; THYNE, M.; DAVIES, S. An investigation into customer satisfaction levels in the budget accommodation sector in Scotland: a case study of backpacker tourists and the Scottish Youth Hostels Association. Tourism Management, p. 525-532, 2006.

NETTO, A. P. Filosofia do turismo: teoria e epistemologia. 2. ed. São Paulo: Aleph, 2011.

PEARCE, P. L.; FOSTER, F. A. University of Travel: Backpacker learning. Tourism Management, Elsevier, v. 28, p. 1285-1298. ISSN DOI: 10.1016/j.tourman.2006.11.009, 2007.

RICHARDSON, R. J. Pesquisa Social - Métodos e Técnicas. 3. ed. São Paulo: Atlas, 2008.

SANTOS, G. E. O.; REJOWSKI, M. Comunicação científica em turismo no Brasil: análises descritivas de periódicos nacionais entre 1990 e 2012. Revista Brasileira de Pesquisa em Turismo, v. 7, n. 1, p. 149$167,2013$.

SANTOS, M. Técnica, Espaço, Tempo. São Paulo: Edusp, 2013.

SEBRAE. Resposta Técnica: meios de hospedagem alternativos. Brasília: SEBRAE, 2014.

SILVA, M. C. D. Hospedaria Vasque. Cultura, Raça, Gênero e Expediente num Oásis da Mauritânia. Etnográfica, Lisboa, v. 10, n. 2, p. 355-381, 2006.

SOARES, M. B.; MACIEL, F. P. Alfabetização. Brasília: Instituto Nacional de Estudos e Pesquisas Educacionais Anísio Teixeira, 2000.

THE EUROPEAN CONSUMER CENTRES' NETWORK. Classification of hotel stablishments within the EU. Nicosia. 2009.

TROTTA, J. Educação e Correlação II - Experiência Internacional e Regional. Os Albergues da Juventude para Jovens e "Jovens de Espírito". Rio de Janeiro: Cia. Brasileira de Artes Gráficas, 1978.

UNIVERSIDADE DO VALE DO ITAJAÍ. Revistas Internacionais Área Tourism, Hospitality e Leasure. Mestrado Acadêmico em Turismo e Hotelaria, 2015. Disponível em: 〈http://www.univali.br/ensino/ pos-graduacao/mestrado/mestrado-academico-em-turismo-e-hotelaria/qualis-capes/Documents/ Ranking\%20Revistas\%20-\%20TH\%20Internacionais.pdf . Acesso em: 27 ago. 2015.

UNWTO. AM Reports: The power of youth travel. United Nations World Tourism Organization. Madrid. 2010.

UNWTO. Youth Travel Matters - Understanding the Global Phenomenon of Youth Travel. Madrid: United Nations World Tourism Organization, 2008.

VIEIRA, E. V.; CÂNDIDO, I. Glossário Técnico Gastronômico, hoteleiro e turístico. 2. ed. Caxias do Sul: Educs, 2003.

VOSGERAU, D. S. R.; ROMANOWSKI, J. P. Estudos de revisão: implicações conceituais e metodológicas. Revista Diálogo Educacional, Curitiba, v. 14, n. 41, p. 165-189, jan./abr. 2014. ISSN: 1518-3483. 